Article

\title{
Language Problems and ADHD Symptoms: How Specific Are the Links?
}

\author{
Erin Hawkins *, Susan Gathercole, Duncan Astle, The CALM Team and Joni Holmes \\ MRC Cognition and Brain Sciences Unit, Cambridge, CB2 7EF, UK; susan.gathercole@mrc-cbu.cam.ac.uk (S.G.); \\ duncan.astle@mrc-cbu.cam.ac.uk (D.A.); joni.holmes@mrc-cbu.cam.ac.uk (J.H.) \\ * Correspondence: erin.hawkins@mrc-cbu.cam.ac.uk; Tel.: +44-1-223-273-686
}

Academic Editor: Paul E. Engelhardt

Received: 16 July 2016; Accepted: 14 October 2016; Published: 21 October 2016

\begin{abstract}
Symptoms of inattention and hyperactivity frequently co-occur with language difficulties in both clinical and community samples. We explore the specificity and strength of these associations in a heterogeneous sample of 254 children aged 5 to 15 years identified by education and health professionals as having problems with attention, learning and/or memory. Parents/carers rated pragmatic and structural communication skills and behaviour, and children completed standardised assessments of reading, spelling, vocabulary, and phonological awareness. A single dimension of behavioural difficulties including both hyperactivity and inattention captured behaviour problems. This was strongly and negatively associated with pragmatic communication skills. There was less evidence for a relationship between behaviour and language structure: behaviour ratings were more weakly associated with the use of structural language in communication, and there were no links with direct measures of literacy. These behaviour problems and pragmatic communication difficulties co-occur in this sample, but impairments in the more formal use of language that impact on literacy and structural communication skills are tied less strongly to behavioural difficulties. One interpretation is that impairments in executive function give rise to both behavioural and social communication problems, and additional or alternative deficits in other cognitive abilities impact on the development of structural language skills.
\end{abstract}

Keywords: ADHD; attention; hyperactivity; learning; language; communication

\section{Introduction}

Symptoms of inattention and hyperactivity typically co-occur with poor communication skills [1,2] and low levels of literacy [3-5] in children with attention deficit hyperactivity disorder (ADHD). The same comorbidities are also found in the general school population $[6,7]$ and in other neurodevelopmental conditions including autism spectrum disorder (ASD) [8], specific language impairment (SLI) [9], and dyslexia [10,11]. These overlapping symptom profiles may reflect dimensions of inattentive and hyperactive behaviour and cognitive difficulties that cut across traditional diagnostic categories [12-14]. In the current study we adopt a dimensional approach to test the specificity of the associations between these dimensions of behaviour, communication and literacy skills in a large sample of children receiving support from specialist services for difficulties in attention, learning and/or memory. The sample included a small number of children with diagnosed developmental disorders and a substantial number with sub-clinical difficulties. The atypical and heterogeneous nature of the sample enabled us to investigate the extent to which impairments in language and behaviour co-occurred in children with problems related to educational progress.

Difficulties in both the formal learning of language structure and the use of language in different contexts are common in developmental disorders [1,15-17]. Structural aspects of language include the use of phonology, semantics, syntax and morphology. These skills are important for literacy 
development [18,19] and for expressing and understanding spoken language in communication [20]. Pragmatic aspects of language involve the appropriate use of language in social communicative contexts such as maintaining appropriate topics, not talking excessively, turn-taking in conversations and interpreting non-verbal cues of others [21,22]. It is unclear whether impairments in pragmatic language arise as a secondary consequence of structural language problems [23] or instead reflect social or behavioural difficulties $[7,24]$. Evidence that children can have pragmatic language difficulties in the absence of problems with language structure supports the view that these two dimensions of language impairment may have different sources $[22,25]$.

Profiles of structural and pragmatic language difficulties differ across specific diagnostic groups. For example, pragmatic language impairments are common in high-functioning autism [16] and ADHD $[1,6,21,26]$, but structural language difficulties are more common in children with reading difficulties and SLI $[12,14,27]$. However, there is also considerable heterogeneity within each diagnostic category, as demonstrated for example by the prevalence of pragmatic language difficulties among children with SLI [28]. There is also substantial overlap between the linguistic profiles of children with different diagnoses, illustrated by the prevalence of pragmatic language difficulties in both children with ADHD and those with autism [1]. These two groups also show elevated symptoms of both inattention and hyperactivity typically common in both disorders [29-31], illustrating how symptom profiles of language and behaviour problems may not be specific to particular disorders.

Pragmatic communication problems are also associated with the severity of symptoms of inattention and hyperactivity in other clinical and typically developing populations [1,6,21]. A possible source of these co-morbid problems are the executive function difficulties frequently observed in children with attentional symptoms of ADHD [32,33]. It has been suggested that ADHD may arise from disruptions to two functionally distinct neurodevelopmental systems: cool cognitive-based functions that include working memory, planning, and inhibition, and which are associated with inattention; and hot affective processes that are associated with delay aversion and impulsive behaviours [34]. Effective pragmatic communication may also rely on both of these systems. Cool cognitive functions may be required to maintain information about the conversational topic and to produce coherent, well-planned and appropriate conversational speech [2,35,36], whilst affective processes may be required for appropriate turn taking, and to limit excessive talking [2,37]. Deficits in one or both of these dimensions may therefore impair pragmatic communication and cause problems with social and peer relationships [7,38]. Consistent with this, research has shown that children with elevated symptoms of inattention and hyperactivity have intact knowledge of pragmatics but problems in the executive skills needed to apply it in social contexts [2,6,39].

Impairments in language structure also co-occur with ADHD symptoms across different populations. Deficits in structural components of communication such as the use of syntax and phonology are present in children with ADHD [2]. Weak literacy skills are also associated with both elevated levels of inattention and hyperactivity in clinical and community samples [40-44], with stronger links with inattention [45-48]. A possible explanation for this association is that behavioural inattention disrupts the formal acquisition of reading skills through its impact on classroom behaviour, which reduces children's ability to attend to direct instructions required for learning to read [49]. This model is supported by evidence that preschool inattention predicts later reading skills independently from other early markers of literacy development such as phoneme awareness and letter knowledge [40,41,50]. Difficulties paying attention may also have a direct effect on the development of structural language skills that are important for literacy development (e.g., phonological processing) [51-53]. An alternative possibility is that underlying deficits in executive functions such as working memory underlie both short attention spans and literacy problems $[3,32,33]$.

Pragmatic and structural language problems encompassing poor structural communication and literacy therefore co-occur with the symptoms of ADHD, but evidence for the specificity and strengths of these relationships is mixed. To date, studies have focused on either diagnosed groups or community samples containing large numbers of typically developing children. The present study explored the 
relationship between these dimensions of impairment across diagnostic categories in a unique sample of struggling learners. The children had difficulties in attention, learning, or memory, and were receiving support from professionals working in children's services, including speech and language therapists, educational psychologists, school-based special educational needs co-ordinators, mental health practitioners, and paediatricians. Approximately one third had received formal diagnoses (e.g., of ADHD, ASD, or dyslexia) and the remainder had sub-clinical difficulties of varying severity. Based on previous findings of an association between behavioural problems and pragmatic language difficulties we expected behaviour problems to be more highly linked with pragmatic than structural language skills overall, with additional specific associations between behavioural inattention and assessments of structural language skills in literacy.

Assessments included standardised tests of reading, spelling, phonological awareness and vocabulary, as well as parent ratings of children's behaviour and pragmatic and structural communication skills. Because of the atypicality of this sample, a data driven approach was used to examine the relationships between behaviour and language skills. We sought to identify whether separate dimensions of inattentive and hyperactive behaviour problems were present in the sample, and the extent to which these behaviours were related to poor structural and pragmatic language skills.

\section{Method}

\subsection{Participants}

Participants were recruited from an ongoing study at the Cambridge Centre for Attention, Learning, and Memory (CALM) based in the MRC Cognition and Brain Sciences Unit in Cambridge, UK. Children were referred to the CALM research clinic for problems in one or more areas of attention, learning, and memory. The current sample consisted of the first 254 children seen in the clinic for whom there were complete data. The age range of the sample was 5:5-15:11 $(M=9: 4, S D=2: 3)$, with 169 males and 85 females. No diagnosis was reported for the majority of the sample $(n=191)$. Twenty children had a diagnosis of ADHD, and a further 59 children had been identified with other developmental learning disorders (e.g., dyslexia, dyscalculia, autism spectrum disorders) or psychiatric diagnoses (see Table 1). Exclusion criteria for referrals to the clinic were: (i) significant and severe known problems in vision or hearing that are uncorrected; and (ii) a native language other than English. Ethical approval was provided by the Local NHS Research Ethics Committee, reference 13/EE/0157. Written informed consent was obtained from parents/guardians, and informed verbal assent was obtained from children.

\subsection{Procedure}

Children completed a battery of tests on a one-to-one basis with a researcher in a dedicated child-friendly testing room at the CALM clinic. These included a wide range of standardised assessments of learning and cognition. Regular breaks were included throughout the session. Testing was split over two sessions for children who struggled to complete the assessments in one sitting. Parents/carers completed a set of questionnaires relating to behaviour, learning, communication, and medical and family history in a family waiting area while their child was assessed. Measures of behaviour, communication skills, and literacy are reported here.

\subsection{Measures}

\section{Behaviour}

Parent ratings of behaviour

The Conners 3 Parent Short Form [54] is a questionnaire assessing behavioural and cognitive problems related to ADHD. Parents or caregivers rated 45 items as not true at all (0); just a little true (1); pretty much true (2); or very much true (4). Scores on these items formed six subscales consisting 
of Inattention, Hyperactivity, Learning Problems, Executive Function, Aggression, and Peer Relations. The sum of raw scores on each subscale was converted to a T-score $(M=50, S D=10)$ for a normative sample 6:00-18:00 years of age. If children's age fell outside the standardisation range the closest age match was used. T-scores $\geq 70$ on an individual subscale indicate the child has very elevated behavioural problems for their age. T-scores 60-69 are within the elevated range, scores 40-59 are in the average range, and scores $\leq 39$ indicate a child has fewer reported problems than average for their age.

Table 1. Sample referral and diagnoses.

\begin{tabular}{|c|c|c|c|}
\hline Referrer & Male & Female & Total \\
\hline SENCo & 103 & 58 & 161 \\
\hline Specialist Teacher & 8 & 5 & 13 \\
\hline Educational Psychologist & 4 & 2 & 6 \\
\hline Speech and Language Therapist & 13 & 9 & 22 \\
\hline Clinical Psychologist & 13 & 7 & 20 \\
\hline Paediatrician & 22 & 4 & 26 \\
\hline Diagnosis & Male & Female & Total \\
\hline None & 105 & 59 & 164 \\
\hline ADD & 2 & 2 & 4 \\
\hline ADHD & 16 & 4 & 20 \\
\hline ASD & 11 & 1 & 12 \\
\hline DAMP & 2 & 1 & 3 \\
\hline Depression & 0 & 2 & 2 \\
\hline Dysgraphia & 1 & 0 & 1 \\
\hline Dyslexia & 13 & 5 & 18 \\
\hline Dyspraxia & 6 & 3 & 9 \\
\hline FASD & 1 & 2 & 3 \\
\hline Generalised Developmental Delay & 1 & 1 & 2 \\
\hline Global Delay, Dyspraxia & 1 & 0 & 1 \\
\hline Hyperactivity & 1 & 0 & 1 \\
\hline OCD & 0 & 1 & 1 \\
\hline Social Anxiety Disorder, Depression & 0 & 1 & 1 \\
\hline Tourettes & 1 & 0 & 1 \\
\hline Primary Reason for Referral & Male & Female & Total \\
\hline Attention & 34 & 12 & 46 \\
\hline Literacy & 30 & 11 & 41 \\
\hline Maths & 6 & 3 & 9 \\
\hline Language & 16 & 7 & 23 \\
\hline Poor academic progress & 53 & 41 & 94 \\
\hline Memory & 20 & 8 & 28 \\
\hline Anxiety & 1 & 0 & 1 \\
\hline
\end{tabular}

Note. The following datapoints were missing: Referral route, 6 data points; Diagnosis, 11 data points; Primary Reason for Referral, 12 datapoints. Abbreviations: SENCo-Special Educational Needs Coordinator; ADD-Attention Deficit Disorder; ADHD-Attention Deficit Hyperactivity Disorder; ASD-Autism Spectrum Disorder; DAMP-Deficits in Attention and Motor Perception; FASD-Fetal Alcohol Spectrum Disoder; OCD-Obsessive Compulsive Disorder.

\subsection{Literacy}

\subsubsection{Reading}

The Single-Word Reading subtest on the Wechsler Individual Achievement Test II (WIAT-II) [55] assessed children's reading abilities. Children read a list of words aloud that were scored by the examiner. Responses were coded as correct if they were pronounced correctly and fluently. Standard scores $(M=100, S D=15)$ were derived from the raw scores, with a normative sample age range of 4:00-16:11. 


\subsubsection{Spelling}

The Spelling sub-test on the WIAT-II provided a measure of spelling attainment. Children were asked to spell words spoken one at a time by the examiner. Raw scores were converted to standard scores $(M=100, S D=15)$ with a normative sample 4:00-16:11 years of age.

\subsubsection{Vocabulary}

The Peabody Picture Vocabulary Test, Fourth Edition (PPVT-4) [56] assessed receptive vocabulary knowledge. Children were required to select one of four pictures showing the meaning of a spoken word. Standard scores were calculated $(M=100, S D=15)$, and the normative sample had an age range of 2:6-90:00.

\subsubsection{Phonological awareness}

The Alliteration subtest of the Phonological Assessment Battery (PhAB) [57] tested phonological awareness. Sets of three spoken words were read aloud and children were required to judge which two words started with the same sound. The number of correct responses formed raw scores, which were converted to standardised scores $(M=100, S D=15)$. Children who were too young or unable to complete the Alliteration subtest were given the Alliteration Test with Pictures subtest. In this version children saw pictures corresponding to words named aloud by the researcher. Children had to indicate which two pictures corresponded to words starting with the same sound. Raw scores on the Alliteration Test with Pictures were converted to standardised scores $(M=100, S D=15)$. If a child's age fell outside the standardisation range (6:00-14:11) the closest age match was used to obtain a standardised score.

\subsection{Communication}

The Children's Communication Checklist, second edition (CCC-2) [58] was used to measure communication skills. This 70-item questionnaire assessed language structure and form, and verbal and nonverbal pragmatic communication. Scaled scores $(M=10, S D=3)$ were derived for 10 subscales that fell into three categories measuring different aspects of language use. The first four scales were (A) Speech; (B) Syntax; (C) Semantics; and (D) Coherence. These assessed language structure, vocabulary use, and discourse, and are areas of communication typically impaired in children with SLI. The next four scales were (E) Inappropriate Initiation; (F) Stereotyped Language; (G) Use of Context; and $(\mathrm{H})$ Nonverbal Communication. These indexed verbal and nonverbal pragmatic communication skills. The final two scales, (I) Social relations; and (J) Interests, assessed aspects of language behaviour that are usually impaired in ASD. Clinically significant communication impairments on the CCC-2 are interpreted using percentiles rather than scaled scores. Scores below the 15th percentile, corresponding approximately to a scaled score of 6, are considered below normal limits (see [58] for further details). For the present purposes, scaled scores $\leq 6$ are considered as corresponding to deficits. The normative sample had an age range of 4:0-16:11.

\section{Results}

\subsection{Analysis Plan}

To characterise our sample we first compared performance on each measure to the age-normed population mean, calculated the proportion of children in the deficit range on each measure, and checked for gender differences in performance. The following Bonferroni corrected significance thresholds were used to correct for multiple comparisons: behaviour, $p<0.008$; communication, $p<0.005$; literacy, $p<0.0125$.

To assess the specificity and strength of links between ADHD behaviours and language skills we first conducted correlation analyses between each measure individual measure. Next, 
we used exploratory factor analysis (EFA) to reduce the dimensionality of the data and identify the underlying constructs of language and behaviour. One EFA was conducted for the behaviour measure. The language measures were entered into two separate EFAs, one for the parent/carer ratings of communication and another for the direct assessments of literacy. Principal axis factoring with direct Oblimin rotation was used to allow factors to be correlated. Factors were chosen based on an eigenvalue cut-off of 1 and examination of the scree plots.

Resulting factor scores were correlated to explore the associations between different dimensions of impairment. Partial correlations were also computed that controlled for age. The relative strength of the associations between each pair of factors was tested using Meng's Z test, which is used to compare correlation coefficients [59]. For all analyses involving the communication data, scores were excluded for children whose CCC-2 ratings were identified as invalid due to disproportionately negative or positive responses [58].

\subsection{Descriptive Statistics}

Descriptive statistics are presented in Table 2. Relative to standardised age-norms, the sample had significantly poorer language and communication skills, and significantly elevated behavioural problems across all of the measures. Comparison of standard scores indicated that children had substantially more behaviour problems, poorer spoken communication and poorer reading, spelling, and phonological skills. This is to be expected given how the sample was recruited. Independent $t$-tests comparing scores for males and females on each measure indicated gender differences only on the literacy measures of vocabulary and phonological skills, in which males scored higher. No gender differences were present across the behaviour and communication measures, or in the literacy measures of reading and spelling.

\subsection{Correlational Analyses}

Correlations between the behaviour and communication measures are presented in Table 3. The majority of the behaviour measures showed a significant negative correlation with the communication measures, indicating that children with poorer behaviour had weaker communication skills. Correlations between Inattention and Speech, and between Executive Function, Speech and Syntax, were not significant.

Table 4 shows the correlations between behaviour and the literacy measures. Literacy skills were negatively associated with ratings of Learning Problems, showing that children rated as poorer learners had lower scores on the direct measures of literacy skills. There were no other significant relationships between behavioural difficulties and literacy.

The correlations between the literacy and communication measures are presented in Table 5 . Reading, spelling, and vocabulary were positively correlated with the majority of the communication measures, indicating that children rated as having better communication skills performed better on these direct assessments of literacy. Phonological awareness was positively correlated only with the parent-rated structural communication scales of speech, syntax, and semantics. 
Table 2. Sample descriptive statistics.

\begin{tabular}{|c|c|c|c|c|c|c|c|c|c|c|c|c|c|c|}
\hline & \multicolumn{7}{|c|}{ Whole Sample } & \multicolumn{7}{|c|}{ Gender Split } \\
\hline & $N$ & Mean & SD & $\begin{array}{l}\text { Effect } \\
\text { Size }+\end{array}$ & $\begin{array}{l}\text { Percentage of } \\
\text { Children in } \\
\text { Deficit Range }\end{array}$ & Skewness & Kurtosis & $\begin{array}{l}\text { Male } \\
\text { Mean }\end{array}$ & SD & $\begin{array}{l}\text { Female } \\
\text { Mean }\end{array}$ & SD & $\mathbf{t}$ & $\mathrm{p}$ & d \\
\hline Age in months & 254 & 111.830 & 26.804 & & & & & 111.69 & 26.746 & 112.12 & 27.075 & -0.119 & 0.905 & -0.016 \\
\hline \multicolumn{15}{|l|}{ Behaviour (Conners) } \\
\hline Inattention & 253 & 78.522 & 12.281 & 2.560 & 88.9 & -0.978 & -0.014 & 79.435 & 11.468 & 76.718 & 13.640 & 1.576 & 0.117 & 0.216 \\
\hline Hyperactivity & 254 & 70.413 & 16.098 & 1.564 & 71.3 & -0.293 & -1.230 & 71.864 & 15.934 & 67.529 & 16.127 & 2.037 & 0.043 & 0.270 \\
\hline Learning Problems & 254 & 76.228 & 12.017 & 2.383 & 89.8 & -0.540 & -0.789 & 74.929 & 12.132 & 78.812 & 11.420 & -2.454 & 0.015 & -0.330 \\
\hline Executive Function & 254 & 72.047 & 13.235 & 1.898 & 81.5 & -0.412 & -0.767 & 72.308 & 12.412 & 71.529 & 14.801 & 0.417 & 0.678 & 0.057 \\
\hline Aggression & 254 & 60.961 & 16.778 & 0.819 & 43.7 & 0.668 & -1.036 & 61.615 & 16.773 & 59.659 & 16.811 & 0.877 & 0.382 & 0.117 \\
\hline Peer Relations & 254 & 70.421 & 18.708 & 1.423 & 63.4 & -0.377 & -0.979 & 71.811 & 18.639 & 67.659 & 18.646 & 1.675 & 0.095 & 0.223 \\
\hline \multicolumn{15}{|l|}{ Communication (CCC-2) } \\
\hline Speech & 248 & 5.528 & 3.991 & -1.279 & 61.7 & 0.300 & -1.056 & 5.484 & 3.948 & 5.863 & 4.217 & -0.663 & 0.508 & -0.093 \\
\hline Syntax & 248 & 5.436 & 4.131 & -1.280 & 63.9 & 0.340 & -1.083 & 5.369 & 4.021 & 5.849 & 4.462 & -0.813 & 0.417 & -0.113 \\
\hline Semantics & 248 & 4.492 & 3.421 & -1.716 & 76.5 & 0.873 & 0.302 & 4.331 & 3.350 & 4.932 & 3.713 & -1.222 & 0.223 & -0.170 \\
\hline Coherence & 248 & 4.682 & 3.017 & -1.768 & 75.7 & 0.741 & 0.506 & 4.618 & 3.083 & 4.822 & 3.133 & -0.465 & 0.642 & -0.066 \\
\hline Inappropriate initiation & 248 & 6.077 & 3.053 & -1.296 & 57.4 & 0.509 & 0.057 & 5.834 & 3.065 & 6.507 & 3.056 & -1.550 & 0.122 & -0.220 \\
\hline Stereotyped language & 246 & 6.155 & 3.401 & -1.202 & 53.9 & 0.300 & -0.528 & 6.089 & 3.483 & 6.380 & 3.437 & -0.587 & 0.558 & -0.084 \\
\hline Use of context & 248 & 4.617 & 3.630 & -1.624 & 72.6 & 0.733 & 0.076 & 4.612 & 3.770 & 4.822 & 3.645 & -0.398 & 0.691 & -0.057 \\
\hline Nonverbal communication & 248 & 5.371 & 3.520 & -1.420 & 64.3 & 0.499 & -0.392 & 5.312 & 3.614 & 5.534 & 3.363 & -0.443 & 0.658 & -0.064 \\
\hline Social relations & 248 & 5.488 & 4.128 & -1.266 & 58.7 & 0.278 & -1.141 & 5.229 & 4.255 & 6.356 & 4.087 & -1.893 & 0.060 & -0.270 \\
\hline Interests & 248 & 6.137 & 2.939 & -1.301 & 61.7 & 0.828 & 0.866 & 5.847 & 2.820 & 6.890 & 3.247 & -2.487 & 0.014 & -0.344 \\
\hline \multicolumn{15}{|l|}{ Literacy } \\
\hline Reading & 253 & 85.455 & 17.354 & -0.899 & 50.2 & 0.103 & -0.449 & 86.148 & 17.989 & 84.060 & 16.012 & 0.901 & 0.368 & 0.123 \\
\hline Spelling & 251 & 82.406 & 15.111 & -1.169 & 62.2 & -0.293 & 3.217 & 82.249 & 15.911 & 82.732 & 13.400 & -0.237 & 0.813 & -0.033 \\
\hline Vocabulary & 250 & 97.172 & 15.631 & -0.185 & 22.0 & -0.315 & 1.330 & 99.898 & 14.949 & 91.687 & 15.618 & 4.030 & $0.000 * *$ & 0.537 \\
\hline Alliteration & 251 & 90.697 & 10.044 & -0.743 & 32.3 & -0.616 & -0.823 & 92.132 & 9.393 & 87.845 & 10.724 & 3.112 & $0.002 * *$ & 0.426 \\
\hline
\end{tabular}

Note. + The effect size of the difference between the normative sample mean and the current sample mean. The deficit range on each measure was scores falling more than 1 SD below

the normative sample mean. ${ }^{* *}$ denotes significance at the 0.01 level, two-tailed. 
Table 3. Correlations between behaviour ratings and communication subscales.

\begin{tabular}{|c|c|c|c|c|c|c|c|c|c|c|c|c|c|c|c|}
\hline Measure & 1 & 2 & 3 & 4 & 5 & 6 & 7 & 8 & 9 & 10 & 11 & 12 & 13 & 14 & 15 \\
\hline 1. Inattention & & & & & & & & & & & & & & & \\
\hline 2. Hyperactivity/impulsivity & $0.573^{* *}$ & & & & & & & & & & & & & & \\
\hline 3. Learning problems & $0.324 * *$ & $0.172 * *$ & & & & & & & & & & & & & \\
\hline 4. Executive function & 0.596 ** & 0.419 ** & $0.330 * *$ & & & & & & & & & & & & \\
\hline 5. Aggression & $0.338^{* *}$ & 0.530 ** & $0.197^{* *}$ & $0.282 * *$ & & & & & & & & & & & \\
\hline 6. Peer Relations & $0.369 * *$ & $0.332 * *$ & $0.220 * *$ & $0.342 * *$ & $0.372 * *$ & & & & & & & & & & \\
\hline 7. Speech & -0.114 & $-0.141 *$ & $-0.315^{* *}$ & -0.127 & -0.267 ** & $-0.177^{* *}$ & & & & & & & & & \\
\hline 8. Syntax & -0.137 * & -0.180 ** & $-0.361^{* *}$ & -0.106 & $-0.295 * *$ & $-0.201 * *$ & $0.689^{* *}$ & & & & & & & & \\
\hline 9. Semantic & $-0.198 * *$ & -0.183 ** & $-0.398^{* *}$ & -0.139 * & $-0.207^{* *}$ & $-0.291 * *$ & $0.574^{* *}$ & $0.617^{* *}$ & & & & & & & \\
\hline 10. Coherence & $-0.316^{* *}$ & $-0.299 * *$ & $-0.338 * *$ & $-0.300 * *$ & $-0.350 * *$ & $-0.405 * *$ & 0.543 ** & $0.635^{* *}$ & $0.690 * *$ & & & & & & \\
\hline 11. Inappropriate initiation & $-0.429 * *$ & $-0.539 * *$ & $-0.302 * *$ & $-0.376 * *$ & $-0.448 * *$ & $-0.474 * *$ & 0.351 ** & $0.417^{* *}$ & $0.523 * *$ & $0.702 * *$ & & & & & \\
\hline 12. Stereotyped language & -0.382 ** & -0.384 ** & $-0.346^{* *}$ & $-0.344^{* *}$ & -0.402 ** & -0.411 ** & 0.444 ** & 0.523 ** & 0.597 ** & $0.708^{* *}$ & $0.704^{* *}$ & & & & \\
\hline 13. Use of context & $-0.362 * *$ & $-0.319 * *$ & $-0.433 * *$ & $-0.283 * *$ & $-0.432^{* *}$ & $-0.536 * *$ & 0.536 ** & $0.612 * *$ & $0.637^{* *}$ & 0.768 ** & $0.696 * *$ & $0.734 * *$ & & & \\
\hline 14. Nonverbal communication & $-0.332 * *$ & $-0.400 * *$ & $-0.256 * *$ & $-0.349 * *$ & $-0.462 * *$ & $-0.528 * *$ & $0.454^{* *}$ & $0.493 * *$ & $0.478^{* *}$ & 0.663 ** & $0.647^{* *}$ & $0.677^{* *}$ & 0.750 ** & & \\
\hline 15. Social & $-0.402 * *$ & $-0.407^{* *}$ & $-0.260 * *$ & $-0.404 * *$ & $-0.541 * *$ & $-0.676 * *$ & $0.335^{* *}$ & $0.389 * *$ & $0.459 * *$ & $0.623 * *$ & $0.625^{* *}$ & 0.620 ** & 0.708 ** & $0.755^{* *}$ & \\
\hline 16. Interests & $-0.328 * *$ & $-0.378 * *$ & $-0.202 * *$ & $-0.305 * *$ & $-0.350 * *$ & $-0.455 * *$ & 0.250 ** & $0.297^{* *}$ & $0.444 * *$ & $0.584 * *$ & 0.716 ** & $0.605^{* *}$ & 0.610 ** & $0.601 * *$ & $0.650^{* *}$ \\
\hline
\end{tabular}

Note. 1-6 are the Conners behaviour scales and 7-16 are the CCC-2 communication scales. The correlations including the CCC-2 measures exclude participants for whom the CCC-2 ratings were identified as invalid due to disproportionately positive or negative responses. $N=254$ for correlations within the behaviour subscales, except for correlations with inattention $(N=253)$. $N=230$ for all correlations with the communication subscales, except for inattention with communication $(N=229)$. All correlations with stereotyped language had $N=228$, with the exception of the correlation with inattention which had $N=227$. ${ }^{*}$ denotes significance at the 0.05 level; ** denotes significance at the 0.01 level, two-tailed.

Table 4. Correlations between behaviour ratings and literacy measures.

\begin{tabular}{|c|c|c|c|c|c|c|c|c|c|}
\hline Measure & 1 & 2 & 3 & 4 & 5 & 6 & 7 & 8 & 9 \\
\hline 1. Inattention & & & & & & & & & \\
\hline 2. Hyperactivity/impulsivity & $0.573^{* *}$ & & & & & & & & \\
\hline 3. Learning problems & $0.324^{* *}$ & $0.172 * *$ & & & & & & & \\
\hline 4. Executive function & $0.596^{* *}$ & $0.419^{* *}$ & $0.330^{* *}$ & & & & & & \\
\hline 5. Aggression & $0.338^{* *}$ & $0.530 * *$ & $0.197^{* *}$ & $0.282 * *$ & & & & & \\
\hline 6. Peer Relations & $0.369^{* *}$ & $0.332 * *$ & $0.220 * *$ & 0.342 ** & $0.372^{* *}$ & & & & \\
\hline 7. Reading & 0.008 & -0.022 & $-0.554 * *$ & -0.041 & -0.094 & -0.002 & & & \\
\hline 8. Spelling & -0.050 & -0.038 & $-0.543^{* *}$ & -0.103 & -0.094 & -0.114 & $0.741^{* *}$ & & \\
\hline 9. Vocabulary & -0.032 & 0.009 & $-0.343^{* *}$ & 0.088 & -0.123 & -0.074 & $0.450 * *$ & $0.325^{* *}$ & \\
\hline 10. Phonological Alliteration & -0.010 & 0.027 & $-0.311^{* *}$ & -0.039 & -0.032 & 0.005 & $0.437^{* *}$ & $0.301^{* *}$ & $0.437^{* *}$ \\
\hline
\end{tabular}

Note. 1- 6 are the Conners behaviour scales and 7-10 are the literacy measures. The sample size for the behaviour scales is as in Table 4 . The sample sizes for the literacy measures were as follows. Vocabulary $N=250$; spelling $N=251$, except for with vocabulary $(N=247)$; reading $N=253$, except for with vocabulary $(N=249)$ and spelling $(N=250)$; alliteration $N=251$ except for with vocabulary $(N=247)$, spelling $(N=249)$, and reading $(N=250) .{ }^{*}$ denotes significance at the 0.05 level; ** denotes significance at the 0.01 level, two-tailed. 
Table 5. Correlations between literacy measures and communication subscales.

\begin{tabular}{|c|c|c|c|c|c|c|c|c|c|c|c|c|c|}
\hline Measure & 1 & 2 & 3 & 4 & 5 & 6 & 7 & 8 & 9 & 10 & 11 & 12 & 13 \\
\hline 1. Reading & & & & & & & & & & & & & \\
\hline 2. Spelling & $0.743 * *$ & & & & & & & & & & & & \\
\hline 3. Vocabulary & $0.461^{* *}$ & $0.320 * *$ & & & & & & & & & & & \\
\hline 4. Phonological Alliteration & $0.429 * *$ & $0.274 * *$ & $0.426^{* *}$ & & & & & & & & & & \\
\hline 5. Speech & 0.353 ** & $0.336^{* *}$ & $0.335^{* *}$ & $0.233 * *$ & & & & & & & & & \\
\hline 6. Syntax & $0.414^{* *}$ & $0.358^{* *}$ & $0.438^{* *}$ & $0.311 * *$ & $0.689 * *$ & & & & & & & & \\
\hline 7. Semantic & 0.368 ** & $0.302 * *$ & $0.363 * *$ & $0.154 *$ & $0.574 * *$ & $0.617^{* *}$ & & & & & & & \\
\hline 8. Coherence & $0.236^{* *}$ & $0.225^{* *}$ & $0.288^{* *}$ & 0.105 & $0.543 * *$ & $0.635^{* *}$ & 0.690 ** & & & & & & \\
\hline 9. Inappropriate initiation & $0.136 *$ & $0.145 *$ & $0.193 * *$ & 0.029 & $0.351 * *$ & $0.417 * *$ & $0.523 * *$ & $0.702 * *$ & & & & & \\
\hline 10. Stereotyped language & 0.173 ** & $0.203 * *$ & $0.265^{* *}$ & 0.044 & $0.444^{* *}$ & $0.523 * *$ & $0.597 * *$ & $0.708^{* *}$ & $0.704 * *$ & & & & \\
\hline 11. Use of context & $0.287^{* *}$ & $0.297 * *$ & $0.362 * *$ & 0.125 & 0.536 ** & $0.612 * *$ & $0.637^{* *}$ & $0.768^{* *}$ & $0.696^{* *}$ & $0.734^{* *}$ & & & \\
\hline 12. Nonverbal communication & 0.073 & 0.112 & $0.157 *$ & -0.007 & $0.454 * *$ & $0.493 * *$ & 0.478 ** & $0.663^{* *}$ & $0.647^{* *}$ & $0.677^{* *}$ & $0.750 * *$ & & \\
\hline 13. Social & 0.076 & 0.123 & $0.162 *$ & -0.073 & $0.335 * *$ & $0.389 * *$ & $0.459 * *$ & $0.623 * *$ & $0.625 * *$ & $0.620 * *$ & $0.708^{* *}$ & $0.755 * *$ & \\
\hline 14. Interests & 0.077 & 0.093 & 0.082 & -0.152 * & 0.250 ** & $0.297 * *$ & $0.444^{* *}$ & $0.584^{* *}$ & 0.716 ** & 0.605 ** & 0.610 ** & $0.601 * *$ & $0.650^{* *}$ \\
\hline
\end{tabular}

Note. The correlations including the CCC-2 measures exclude participants for whom the CCC-2 ratings were identified as invalid due to disproportionately positive or negative responses. The correlations with literacy here thus only include participants with valid CCC- 2 ratings. * denotes significance at the 0.05 level; ${ }^{* *}$ denotes significance at the 0.01 level, two-tailed. 


\subsection{Exploratory Factor Analyses}

Tables 6-8 show the component matrices for parent ratings of behaviour and communication, and the literacy measures respectively. In all factor analyses, eigenvalues below 0.40 were suppressed.

Table 6. Exploratory factor analysis on the Conners behaviour subscales.

\begin{tabular}{cc}
\hline Behaviour Measures & Factor 1 \\
\hline Inattention & 0.783 \\
Hyperactivity/impulsivity & 0.707 \\
Executive Functions & 0.664 \\
Aggression & 0.554 \\
Peer Relations & 0.517 \\
Learning Problems & \\
\hline
\end{tabular}

Note. Factor loadings lower than 0.4 are not shown.

Table 7. Exploratory factor analysis on the CCC-2 communication subscales.

\begin{tabular}{ccc}
\hline Communication Measures & Factor 1 & Factor 2 \\
\hline Interests & 0.892 & \\
Social & 0.838 & \\
Inappropriate Initiation & 0.835 & \\
Nonverbal & 0.749 & \\
Stereotyped language & 0.682 & \\
Use of context & 0.659 & \\
Coherence & 0.553 & 0.423 \\
Syntax & & 0.856 \\
Speech & & 0.814 \\
Semantics & & 0.579 \\
\hline
\end{tabular}

Note. Factor loadings lower than 0.4 are not shown.

Table 8. Exploratory factor analysis on the literacy measures.

\begin{tabular}{cc}
\hline Literacy Measures & Factor $\mathbf{1}$ \\
\hline Reading & 0.950 \\
Spelling & 0.712 \\
Vocabulary & 0.528 \\
Alliteration & 0.505 \\
\hline
\end{tabular}

Note. Factor loadings lower than 0.4 are not shown.

A one-factor solution emerged for the behaviour ratings, which explained $37.94 \%$ of the variance. The Inattention and Hyperactivity subscales loaded most highly on this factor, with moderate loadings of Executive Function, Aggression and Peer Relations. The Learning Problems subscale was excluded as it did not have a sufficiently high loading.

A two-factor solution emerged for the communication scale. The six subscales measuring pragmatic and social communication loaded on Factor 1, which accounted for $59.71 \%$ of the variance. Three of the four subscales tapping structural communication skills loaded on Factor 2, explaining $9.03 \%$ of the variance. Factor 1 was therefore linked with pragmatic and social aspects of communication, and Factor 2 with structural communication skills. The Coherence variable loaded on both factors (Factor $1=0.553$; Factor $2=0.423$ ), reflecting its sensitivity to both pragmatic and structural communication problems [16,58].

For the direct measures of literacy, a one-factor solution emerged that explained $48.56 \%$ of the variance. Reading and Spelling loaded most highly on this factor, with moderate loadings from Vocabulary and Phonological Alliteration. 


\subsection{Correlations between Factor Scores}

The behaviour factor was strongly negatively associated with both the pragmatic $(r=-0.617$, $p<0.001)$ and structural $(r=-0.322, p<0.001)$ communication factors, indicating that children with more behavioural problems had poorer communication skills (see Table 9 and Figure 1). The relationship between behaviour problems and pragmatic communication skills was significantly stronger than the association between behaviour and structural communication skills (Meng's $\mathrm{Z}=-6.255, p<0.001)$. In line with this, there was no relationship between the behaviour factor and direct measures of language structure as captured by the literacy factor $(r=-0.097, p>0.14)$.

Table 9. Correlations between factor scores.

\begin{tabular}{cccc}
\hline Factor & $\mathbf{1}$ & $\mathbf{2}$ & $\mathbf{3}$ \\
\hline 1. Behaviour Factor & & & \\
2. Literacy Factor & -0.091 & & \\
3. Pragmatic and Social Communication Factor & $-0.617^{* *}$ & $0.168^{*}$ & \\
4. Structural Communication Factor & $-0.322^{* *}$ & $0.456^{* *}$ & $0.656^{* *}$ \\
\hline
\end{tabular}

Note. These correlations were unchanged when controlling for children's age in months. ${ }^{*}$ denotes significance at the 0.05 level; $* *$ denotes significance at the 0.01 level, two tailed.

\section{Relationship between behaviour problems and communication skills}

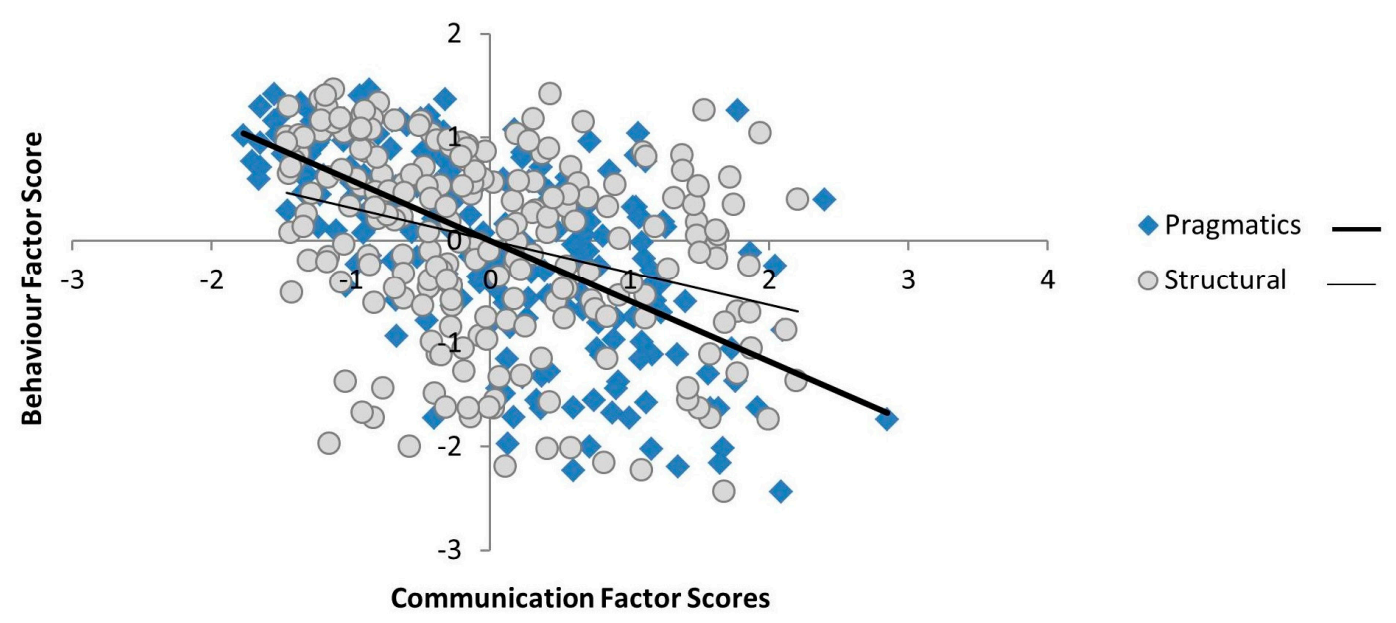

Figure 1. Scatterplots of the correlations between the pragmatic and structural communication factors and behaviour problems.

Literacy was significantly related to both structural $(r=0.455, p<0.001)$ and pragmatic $(r=0.152$, $p<0.05)$ communication factors, indicating that children with better performance on the direct measures of structural language had better parent-reported communication skills. The association between literacy and structural communication skills was significantly stronger than the association between literacy and pragmatics (Meng's $Z=-5.747, p<0.001$ ), indicating that the direct assessments of literacy shared more variance with the parent ratings of structural language in communication (see Figure 2). These patterns of association were unaffected by controlling for age. 


\section{Relationship between literacy and communication skills}

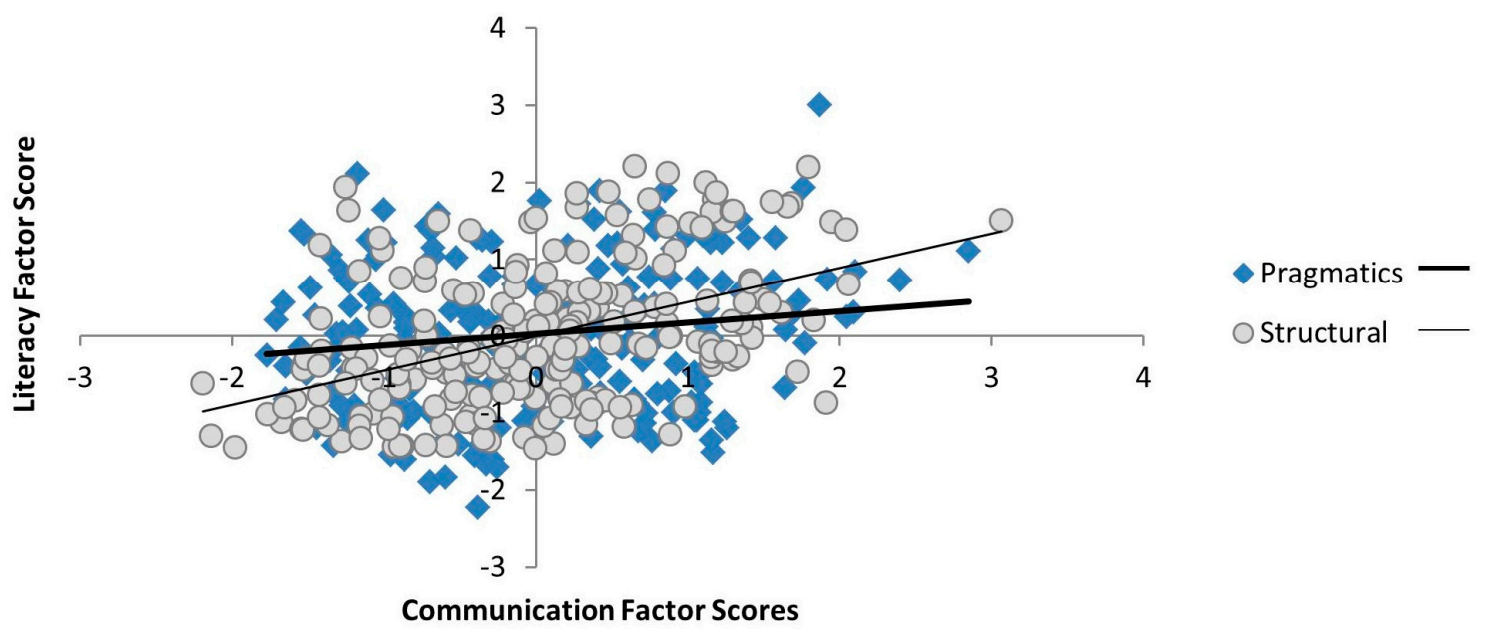

Figure 2. Scatterplots of the correlations between the pragmatic and structural communication factors and literacy.

\section{Discussion}

This study explored associations between the behavioural symptoms of ADHD and pragmatic and structural language abilities in a heterogeneous sample of children receiving support for problems in attention, learning, or memory. A bottom-up data driven approach identified dimensions of behaviour and language characterising the sample. This yielded a single dimension of behavioural problems that included inattention, hyperactivity and other behaviour problems commonly associated with ADHD. Although symptoms of inattention and hyperactivity can be diagnostically separate [60], it was not possible to differentiate them in the current sample. Three related dimensions of language emerged. One captured pragmatic communication skills and two encompassed children's use of language structure. These were structural communication and literacy. Behaviour problems were strongly associated with pragmatic aspects of language, but less so with structural communication skills and not at all with literacy.

These differences in the relationship between the pragmatic and structural aspects of language function and behaviour are consistent with the idea that language impairments may have different sources $[22,25]$. Co-occurring behaviour difficulties and pragmatic communication problems may be underpinned by a common deficit in executive functioning. Pragmatic skills such as taking turns in conversation and not talking excessively, and the ability to control hyperactive/impulsive behaviours may both rely on hot executive skills like self-regulation and inhibition [2,37]. Likewise, features of social interaction such as monitoring and maintaining appropriate topics of conversation, and planning coherent speech, may draw on the same cool executive functions needed to maintain focussed attention (e.g., working memory) [61]. Consistent with this interpretation, executive function problems were present in the behaviour ratings in our sample. An alternative explanation is that there is a direct link between poor behaviour and weak pragmatic skills. By this account, difficult behaviour might directly limit opportunities for social interaction at home or school, impairing the development of social language skills $[24,38]$. Our sample had problems with peer relationships, signalling that they may indeed have had fewer opportunities to practice or develop pragmatic language skills.

Impairments in language structure may arise from different or additional sources to pragmatic and behavioural problems. Consistent with this, there was a weaker association between structural communication and behaviour than between pragmatics and behaviour. Moreover, literacy was unrelated to behaviour. This was unexpected given previous evidence linking ADHD symptoms, and in particular inattentive behaviour, with language and reading abilities [41,49]. One possibility 
is that the cognitive deficits limiting the acquisition and development of linguistic knowledge and skills are different to the executive function problems that are affecting behavioural control and social communication in our sample. These additional or alternative deficits might include problems with phonological processing. Supporting this idea, in the current study children's phonological awareness and abilities in reading and spelling were strongly associated, but there was no link between their behavioural attention problems and phonological skills. Phonological processing skills are important for literacy development [14] and difficulties with phonological processing influence the acquisition of letter-sound correspondences that are important for learning to read [27,40]. Phonological processing impairments are commonly observed in children with SLI who have structural language impairments [12]. However, children with elevated symptoms of ADHD or pragmatic language difficulties tend to have intact phonological processing skills unless they have co-morbid problems with language structure $[62,63]$, suggesting phonological deficits may be more closely associated with broader structural language problems than pragmatic difficulties.

There were stronger links between the parent-reported measures of language and behaviour than between parent-rated behaviour and the direct tests of literacy. This raises the possibility that the associations between parent-rated communication and behaviour simply reflect common variance in subjective reports from parents / carers of children who are receiving support from professional services. Although we cannot rule out this possibility, several features of the data suggest the parent ratings provided meaningful measurements of children's behaviour and language skills. Firstly, the parent ratings of communicative language were related to the standardised literacy assessments, with a stronger relationship between parent-rated structural communication and direct literacy measures than between pragmatic communication and literacy. Second, these parent-rated communication scores similarly showed different strengths of association with parents' behaviour ratings. Finally, parents' views of their children's learning abilities, as measured by a subscale of the behaviour checklist, correlated with the direct measures of literacy despite there being no other relationships between these measures and other scales on the behaviour checklist. Taken together, the specificity of these links speaks against a common variance in the parent measures underpinning the results.

\section{Conclusions}

In summary, the phenotype of these children with problems in attention, learning or memory was characterised by a broad dimension of inattentive and hyperactive behaviour that was strongly associated with pragmatic language difficulties, and more weakly associated with difficulties in the use of language structure. The comorbidities between behavioural symptoms and pragmatic language problems may reflect a cluster of developmental problems underpinned by deficits in executive function difficulties [2], while problems with language structure may arise through difficulties in phonological processing. From a practical perspective, these findings suggest that different profiles of language impairment may require different intervention approaches. Pragmatic communication problems may benefit from behavioural interventions, such as psychosocial therapy or executive function-based interventions [64,65]. Approaches targeting other cognitive difficulties, such as phonological weaknesses [66] might be more beneficial than behavioural interventions for problems in language structure.

Acknowledgments: The Centre for Attention Learning and Memory (CALM) research clinic at the MRC Cognition and Brain Sciences Unit in Cambridge (CBSU) is supported by funding from the Medical Research Council of Great Britain to Duncan Astle, Susan Gathercole and Tom Manly. The clinic is led by Joni Holmes and managed by Francesca Woolgar. Data collection is assisted by a team of PhD students and researchers at the CBSU that includes Joe Bathelt, Sally Butterfield, Amy Johnson, Sinead O’Brien, Sara Gharooni, Sarah Bishop, Laura Forde, Agnieszka Jaroslawska, Erica Bottacin and Gemma Crickmore. The authors wish to thank the many professionals working in children's services in the South-East and East of England for their support, and to the children and their families for giving up their time to visit the clinic. 
Author Contributions: E.H., J.H., D.A. and S.G. conceived the study; the CALM team collected the data; E.H. and J.H. analysed the data; E.H., J.H., D.A., and S.G. interpreted the data; E.H. and J.H. wrote the manuscript with important revisions and support from D.A. and S.G.

Conflicts of Interest: The authors declare no conflicts of interest.

\section{References}

1. Geurts, H.M.; Embrechts, M. Language profiles in ASD, SLI, and ADHD. J. Autism Dev. Disord. 2008, 38, 1931-1943. [CrossRef] [PubMed]

2. Green, B.C.; Johnson, K.A.; Bretherton, L. Pragmatic language difficulties in children with hyperactivity and attention problems: An integrated review. Int. J. Lang. Commun. Disord. 2014, 49, 15-29. [CrossRef] [PubMed]

3. Loe, I.M.; Feldman, H.M. Academic and educational outcomes of children with ADHD. Ambul. Pediatr. 2007, 7, 82-90. [CrossRef] [PubMed]

4. Hart, S.A.; Petrill, S.A.; Willcutt, E.; Thompson, L.A.; Schatschneider, C.; Deater-Deckard, K.; Cutting, L.E. Exploring how symptoms of attention-deficit/hyperactivity disorder are related to reading and mathematics performance: General genes, general environments. Psychol. Sci. 2010, 21, 1708-1715. [CrossRef] [PubMed]

5. Zentall, S.S. Math performance of students with ADHD: Cognitive and behavioral contributors and interventions. In Why is Math so Hard for Some Children? Berch, D.B., Mazzocco, M.M.M., Eds.; Paul H. Brookes: Baltimore, MD, USA, 2007; pp. 219-244.

6. Bignell, S.; Cain, K. Pragmatic aspects of communication and language comprehension in groups of children differentiated by teacher ratings of inattention and hyperactivity. Br. J. Dev. Psychol. 2007, 25, 499-512. [CrossRef]

7. Leonard, M.A.; Milich, R.; Lorch, E.P. The role of pragmatic language use in mediating the relation between hyperactivity and inattention and social skills problems. J. Speech Lang. Hear. Res. 2011, 54, 567-579. [CrossRef]

8. Rommelse, N.N.; Geurts, H.M.; Franke, B.; Buitelaar, J.K.; Hartman, C.A. A review on cognitive and brain endophenotypes that may be common in autism spectrum disorder and attention-deficit/hyperactivity disorder and facilitate the search for pleiotropic genes. Neurosci. Biobehav. Rev. 2011, 35, 1363-1396. [CrossRef] [PubMed]

9. Duinmeijer, I.; Jong, J.; de Scheper, A. Narrative abilities, memory and attention in children with a specific language impairment. Int. J. Lang. Commun. Disord. 2012, 47, 542-555. [CrossRef] [PubMed]

10. Willcutt, E.G.; Pennington, B.F. Comorbidity of reading disability and attention-deficit/hyperactivity disorder differences by gender and subtype. J. Learn. Disabil. 2000, 33, 179-191. [CrossRef] [PubMed]

11. Germano, E.; Gagliano, A.; Curatolo, P. Comorbidity of ADHD and dyslexia. Dev. Neuropsychol. 2010, 35, 475-493. [CrossRef] [PubMed]

12. Bishop, D.V.; Snowling, M.J. Developmental dyslexia and specific language impairment: Same or different? Psychol. Bull. 2004, 130, 858-886. [CrossRef] [PubMed]

13. Coghill, D.; Sonuga-Barke, E.J. Annual research review: Categories versus dimensions in the classification and conceptualisation of child and adolescent mental disorders-implications of recent empirical study. J. Child Psychol. Psychiatry Allied Discip. 2012, 53, 469-489. [CrossRef] [PubMed]

14. Ramus, F.; Marshall, C.R.; Rosen, S.; van der Lely, H.K. Phonological deficits in specific language impairment and developmental dyslexia: Towards a multidimensional model. Brain 2013, 136, 630-645. [CrossRef] [PubMed]

15. Bishop, D.V.M. Development of the Children's Communication Checklist (CCC): A method for assessing qualitative aspects of communicative impairment in children. J. Child Psychol. Psychiatry 1998, 39, 879-891. [CrossRef] [PubMed]

16. Norbury, C.F.; Nash, M.; Baird, G.; Bishop, D. Using a parental checklist to identify diagnostic groups in children with communication impairment: A validation of the children's communication checklist-2. Int. J. Lang. Commun. Disord. 2004, 39, 345-364. [CrossRef] [PubMed]

17. Gilmour, J.; Hll, B.; Skuse, D.H. Social communication deficits in conduct disorder: A clinical and community survey. J. Child Psychol. Psychiatry 2004, 45, 967-978. [CrossRef] [PubMed] 
18. Melby-Lervåg, M.; Lyster, S.-A.H.; Hulme, C. Phonological skills and their role in learning to read: A meta-analytic review. Psychol. Bull. 2012, 138, 322-352. [CrossRef] [PubMed]

19. Nagy, W.E.; Carlisle, J.F.; Goodwin, A. Morphological knowledge and literacy acquisition. J. Learn. Disabil. 2014, 47, 3-12. [CrossRef] [PubMed]

20. Botting, N.; Faragher, B.; Simkin, Z.; Knox, E.; Conti-Ramsden, G. Predicting pathways of specific language impairment: What differentiates good and poor outcome? J. Child Psychol. Psychiatry 2001, 42, 1013-1020. [CrossRef] [PubMed]

21. Bishop, D.V.M.; Baird, G. Parent and teacher report of pragmatic aspects of communication: Use of the Children's Communication Checklist in a clinical setting. Dev. Med. Child Neurol. 2001, 43, 809-818. [CrossRef] [PubMed]

22. Bishop, D.V.M. Pragmatic language impairment: A correlate of SLI, a distinct subgroup, or part of the autistic continuum? In Speech and Language Impairments in Children: Causes, Characteristics, Intervention and Outcome; Bishop, D.V.M., Leonard, L.B., Eds.; Psychology Press: Hove, UK, 2000; pp. 99-113.

23. Redmond, S.M.; Rice, M.L. The socioemotional behaviors of children with SLI: Social adaptation or social deviance? J. Speech Lang. Hear. Res. 1998, 41, 688-700. [CrossRef] [PubMed]

24. Staikova, E.; Gomes, H.; Tartter, V.; McCabe, A.; Halperin, J.M. Pragmatic deficits and social impairment in children with ADHD. J. Child Psychol. Psychiatry Allied Discip. 2013, 54, 1275-1283. [CrossRef] [PubMed]

25. Conti-Ramsden, G.; Crutchley, A.; Botting, N. The extent to which psychometric tests differentiate subgroups of children with SLI. J. Speech Lang. Hear. Res. 1997, 40, 765-777. [CrossRef] [PubMed]

26. Mueller, K.L.; Tomblin, J.B. Examining the comorbidity of language disorders and ADHD. Top. Lang. Disord. 2012, 32, 228-246. [CrossRef] [PubMed]

27. Catts, H.W.; Fey, M.; Tomblin, J.B.; Zhang, X. A longitudinal investigation of reading outcomes in children with language impairments. J. Speech Lang. Hear. Res. 2002, 45, 1142-1157. [CrossRef]

28. Bishop, D.V.M.; Norbury, C.F. Exploring the borderlands of autistic disorder and specific language impairment: A study using standardised diagnostic instruments. J. Child Psychol. Psychiatry 2002, 43, 917-929. [CrossRef] [PubMed]

29. Gadow, K.D.; DeVincent, C.J.; Pomeroy, J. ADHD symptom subtypes in children with pervasive developmental disorder. J. Autism Dev. Disord. 2006, 36, 271-283. [CrossRef] [PubMed]

30. Lee, D.O.; Ousley, O.Y. Attention-deficit hyperactivity disorder symptoms in a clinic sample of children and adolescents with pervasive developmental disorders. J. Child Adolesc. Psychopharmacol. 2006, 16, 737-746. [CrossRef] [PubMed]

31. Sinzig, J.; Walter, D.; Doepfner, M. Attention deficit/hyperactivity disorder in children and adolescents with autism spectrum disorder: Symptom or syndrome? J. Atten. Disord. 2009, 13, 116-126. [CrossRef] [PubMed]

32. Holmes, J.; Hilton, K.A.; Place, M.; Alloway, T.P.; Elliott, J.G.; Gathercole, S.E. Children with low working memory and children with adhd: Same or different? Front. Hum. Neurosci. 2014. [CrossRef] [PubMed]

33. Willcutt, E.G.; Doyle, A.E.; Nigg, J.T.; Faraone, S.V.; Pennington, B.F. Validity of the executive function theory of attention-deficit/hyperactivity disorder: A meta-analytic review. Biol. Psychiatry 2005, 57, 1336-1346. [CrossRef] [PubMed]

34. Castellanos, F.X.; Sonuga-Barke, E.J.; Milham, M.P.; Tannock, R. Characterizing cognition in ADHD: Beyond executive dysfunction. Trends Cogn. Sci. 2006, 10, 117-123. [CrossRef] [PubMed]

35. Engelhardt, P.E.; Ferreira, F.; Nigg, J.T. Priming sentence production in adolescents and adults with attention-deficit/hyper-activity disorder. J. Abnorm. Child Psychol. 2009, 37, 995-1006. [CrossRef] [PubMed]

36. Tannock, R.; Scharchar, R. Executive dysfunction as an underlying mechanism of behavior and language problems in attention deficit hyperactivity disorder. Cambridge University Press: New York, NY, USA, 1996.

37. Martin, I.; McDonald, S. Weak coherence, no theory of mind, or executive dysfunction? Solving the puzzle of pragmatic language disorders. Brain. Lang. 2003, 85, 451-466. [CrossRef]

38. Camarata, S.M.; Gibson, T. Pragmatic language deficits in attention-deficit hyperactivity disorder (ADHD). Ment. Retard. Dev. Disabil. Res. Rev. 1999, 5, 207-214. [CrossRef]

39. Kim, O.H.; Kaiser, A.P. Language characteristics of children with ADHD. Commun. Disord. Quarterly 2000, 21, 154-165. [CrossRef]

40. Dally, K. The influence of phonological processing and inattentive behavior on reading acquisition. J. Educ. Psychol. 2006, 98, 420-437. [CrossRef] 
41. Dittman, C.K. The impact of early classroom inattention on phonological processing and word-reading development. J. Atten. Disord. 2013, 20, 653-664. [CrossRef] [PubMed]

42. Gremillion, M.L.; Martel, M.M. Semantic language as a mechanism explaining the association between ADHD symptoms and reading and mathematics underachievement. J. Abnorm. Child Psychol. 2012, 40, 1339-1349. [CrossRef] [PubMed]

43. Mayes, S.D.; Calhoun, S.L.; Mayes, R.D.; Molitoris, S. Autism and ADHD: Overlapping and discriminating symptoms. Res. Autism Spectr. Disord. 2012, 6, 277-285. [CrossRef]

44. Sciberras, E.; Mueller, K.L.; Efron, D.; Bisset, M.; Anderson, V.; Schilpzand, E.J.; Jongeling, B.; Nicholson, J.M. Language problems in children with ADHD: A community-based study. Pediatrics 2014, 133, 793-800. [CrossRef] [PubMed]

45. Barriga, A.Q.; Doran, J.W.; Newell, S.B.; Morrison, E.M.; Barbetti, V.; Robbins, B.D. Relationships between problem behaviors and academic achievement in adolescents. The unique role of attention problems. J. Emot. Behav. Disord. 2002, 10, 233-240. [CrossRef]

46. Breslau, N.B.J.; Peterson, E.; Miller, E.L.V.C.; Bohnert, K.; Nigg, J.T. Change in teachers' ratings of attention problems and subsequent change in academic achievement: A prospective analysis. Psychol. Med. 2010, 40, 159-166. [CrossRef] [PubMed]

47. Daley, D.; Birchwood, J. ADHD and academic performance: Why does ADHD impact on academic performance and what can be done to support ADHD children in the classroom? Child Care Health Dev. 2010, 36, 455-464. [CrossRef] [PubMed]

48. Chhabildas, N.; Pennington, B.F.; Willcutt, E.G. A comparison of the neuropsychological profiles of the DSM-IV subtypes of ADHD. J. Abnorm. Child Psychol. 2001, 29, 529-540. [CrossRef] [PubMed]

49. Rapport, M.D.; Scanlan, S.W.; Denney, C.B. Attention-deficit/hyperactivity disorder and scholastic achievement: A model of dual developmental pathways. J. Child Psychol. Psychiatry 1999, 40, 1169-1183. [CrossRef] [PubMed]

50. Stephenson, K.A.; Parrila, R.K.; Georgiou, G.K.; Kirby, J.R. Effects of home literacy, parents' beliefs, and children's task-focused behavior on emergent literacy and word reading skills. Sci. Stud. Read. 2008, 12, 24-50. [CrossRef]

51. Arnett, A.B.; Pennington, B.F.; Willcutt, E.; Dmitrieva, J.; Byrne, B.; Samuelsson, S.; Olson, R.K. A cross-lagged model of the development of ADHD inattention symptoms and rapid naming speed. J. Abnorm. Child Psychol. 2012, 40, 1313-1326. [CrossRef] [PubMed]

52. Martinussen, R.; Grimbos, T.; Ferrari, J.L. Word-level reading achievement and behavioral inattention: Exploring their overlap and relations with naming speed and phonemic awareness in a community sample of children. Arch. Clin. Neuropsychol. 2014, 29, 680-690. [CrossRef] [PubMed]

53. Sims, D.M.; Lonigan, C.J. Inattention, hyperactivity, and emergent literacy: Different facets of inattention relate uniquely to preschoolers' reading-related skills. J. Clin. Child Adolesc. Psychol. 2013, 42, 208-219. [CrossRef] [PubMed]

54. Conners, C.K. Conners, 3rd ed.; Multi-Health Systems Inc: New York, NY, USA, 2008.

55. Wechsler, D. Wechsler Individual Achievement Test, 2nd UK ed.; Pearson Education: Minneapolis, MN, USA, 2005.

56. Dunn, L.M.; Dunn, D.M. Peabody Picture Vocabulary Test, 4th ed.; Pearson Education: Minneapolis, MN, USA, 2007.

57. Frederickson, N.; Frith, U.; Reason, R. The Phonological Assessment Battery (PHAB); GL Assessment Ltd: London, UK, 1997.

58. Bishop, D.V.M. The Children's Communication Checklist 2; Psychological Corporation: London, UK, 2003.

59. Meng, X.; Rubin, D.B.; Rosenthal, R. Comparing correlated correlation coefficients. Psychol. Bull. 1992, 111, 172-175. [CrossRef]

60. Association, A.P. Dsm 5; American Psychiatric Association: Arlington, VA, USA, 2013.

61. Kane, M.J.; Brown, L.H.; McVay, J.C.; Silvia, P.J.; Myin-Germeys, I.; Kwapil, T.R. For whom the mind wanders, and when: An experience-sampling study of working memory and executive control in daily life. Psychol. Sci. 2007, 18, 614-621. [CrossRef] [PubMed]

62. Bishop, D.V.; Maybery, M.; Wong, D.; Maley, A.; Hill, W.; Hallmayer, J. Are phonological processing deficits part of the broad autism phenotype? Am. J. Med. Genet. B Neuropsychiatr. Genet. 2004, 128B, 54-60. [CrossRef] [PubMed] 
63. Gooch, D.; Snowling, M.; Hulme, C. Time perception, phonological skills and executive function in children with dyslexia and/or ADHD symptoms. J. Child Psychol. Psychiatry Allied Discip. 2011, 52, 195-203. [CrossRef] [PubMed]

64. Diamond, A.; Barnett, W.S.; Thomas, J.; Munro, S. Preschool program improves cognitive control. Science 2007, 318, 1387-1388. [CrossRef] [PubMed]

65. Abikoff, H.B.; Thompson, M.; Laver-Bradbury, C.; Long, N.; Forehand, R.L.; Miller Brotman, L.; Klein, R.G.; Reiss, P.; Huo, L.; Sonuga-Barke, E. Parent training for preschool ADHD: A randomized controlled trial of specialized and generic programs. J. Child Psychol. Psychiatry Allied Discip. 2015, 56, 618-631. [CrossRef] [PubMed]

66. Snowling, M.J.; Hulme, C. Interventions for children's language and literacy difficulties. Int. J. Lang. Commun. Disord. 2012, 47, 27-34. [CrossRef] [PubMed]

(C) 2016 by the authors; licensee MDPI, Basel, Switzerland. This article is an open access article distributed under the terms and conditions of the Creative Commons Attribution (CC-BY) license (http://creativecommons.org/licenses/by/4.0/). 